\title{
PRODUTO INTERNO VERDE (PIV) COMO ALTERNATIVA PARA A SUSTENTABILIDADE BRASILEIRA
}

Leonardo da Rocha de Souza ${ }^{1}$

Nicolau Cardoso Neto ${ }^{2}$

\begin{abstract}
RESUMO: A sustentabilidade é um tema que há anos vem sendo aprofundado por diferentes áreas do conhecimento. Muitos eventos e convenções internacionais discutiram e ainda discutem o tema, tendo sido formado um sistema jurídico em torno dele. Contudo, um novo fator surgiu em outubro de 2017, com a promulgação da Lei ${ }^{0} 13.493$ que estabeleceu o Produto Interno Verde (PIV), que deverá considerar o cálculo do patrimônio ecológico nacional, além dos critérios e dados tradicionalmente utilizados. Assim, este artigo pretende fazer uma breve análise do advento do PIV como alternativa para a sustentabilidade brasileira e como tentativa de mitigação dos efeitos do capitalismo.
\end{abstract}

PALAVRAS-CHAVE: Sustentabilidade Socioambiental; Políticas Ambientais; Produto Interno Verde; Direitos Fundamentais.

\section{GREEN INTERNAL PRODUCT (PIV) AS AN ALTERNATIVE FOR BRAZILIAN SUSTAINABILITY}

\begin{abstract}
Sustainability is a topic that has been deepened for many years by different areas of knowledge. Many international events and conventions have discussed and still discuss the subject, and a legal system has been formed around it. However, a new factor emerged in October 2017, with the enactment of brazilian Law n. 13.493, which established the Green Internal Product (PIV in portuguese), which should consider the calculation of the national ecological heritage, in addition to the criteria and data traditionally used. Thus, this article intends to make a brief analysis of the advent of PIV as an alternative to Brazilian sustainability and as an attempt to mitigate the effects of capitalism.
\end{abstract}

KEY WORDS: Socio-environmental Sustainability; Environmental Policies; Green Internal Product - PIV; Fundamental rights.

\footnotetext{
${ }^{1}$ Pós-doutor, Doutor e Mestre em Direito. Professor FURB e UCS. Vice-líder grupo pesquisa CNPq/FURB 'Direitos Fundamentais, Cidadania e Justiça'. Integrante linha Sustentabilidade Socioambiental, Ecocomplexidade, Políticas Sanitárias e Ambientais. E-mail: leorochasouza@gmail.com

${ }^{2}$ Doutor em Direito Público, Mestre em Engenharia Ambiental e Ciência Jurídica. Professor da FURB. Integrante de Grupo de Pesquisa na linha Sustentabilidade Socioambiental, Ecocomplexidade, Políticas Sanitárias e Ambientais. E-mail: nicolau@scambiental.com.br
} 


\section{PRODUTO INTERNO VERDE (PIV) COMO ALTERNATIVA PARA A SUSTENTABILIDADE BRASILEIRA}

\section{INTRODUÇÃO}

O capítulo do meio Ambiente na Constituição Federal de 1988 declarou o meio ambiente ecologicamente equilibrado como um direito a ser protegido e tutelado pelo Poder Público e pela coletividade. Essa entonação constitucional revela a preocupação do legislador de que a sustentabilidade seja reconhecida como um direito fundamental, cuja análise compreende seu conteúdo, os sujeitos de direitos e deveres envolvidos, além dos meios de sua efetivação.

A expressão desenvolvimento sustentável, no entanto, como discurso de um ecocapitalismo, como ideologia do industrialismo e do livre mercado, vem gerando, na verdade, um desenvolvimento insustentável. O próprio conceito é um paradoxo, pois a palavra ‘desenvolvimento' “remete às ciências sociais e à economia” está relacionado à “transformação artificial dos habitats da natureza, ao funcionamento urbano do ambiente construído”. Por outro lado, a palavra ‘sustentável’ é própria “da biologia, expressando o funcionamento dos ciclos naturais, dos ecossistemas flexíveis e em equilíbrio”. O problema é que a contradição não se restringe apenas à semântica. Na prática, vem preponderando o desenvolvimento econômico, ligado à visão capitalista e ao seu anseio de “dominação e transformação da natureza bruta”, gerando impactos imprevisíveis, “alterando a sustentabilidade e as relações sociais ou socioambientais”. (PELIZZOLI, 1999, p. 101-102)

O surgimento da Lei $\mathrm{n}^{\circ}$ 13.493, de 17 de outubro de 2017, objeto deste artigo, pode ser uma tentativa de "mudança gradativa mas profunda nas regras do jogo - jogo este que é baseado na dilapidação dos ecossistemas e na exclusão, seja de países periféricos, seja de classes sociais à margem do processo”. Para isso, é claro, não basta a alteração legislativa: serão necessárias modificações relacionadas “aos estilos de vida, práticas de consumo, à auto-organização das localidades e regiões com suas vocações econômicas, ao uso dos recursos imediatos de forma renovável, à máquina da publicidade e mercado, enfim, às demandas dos indivíduos na sociedade contemporânea”. Isso envolve novos hábitos, nova ética, e uma relação diferente “dos sujeitos entre si e com seu mundo", com resultados sentidos na qualidade de vida, na cidadania, na educação e na "cultura como um todo, em vista de uma nova emancipação para os excluídos”. (PELIZZOLI, 1999, p. 103-105)

O objetivo deste artigo é verificar o momento, nessa mudança gradativa, do advento do Produto Interno Verde - PIV, instituído pela Lei $\mathrm{n}^{\circ}$ 13.493, de 17 de outubro de 2017. Inicialmente, parece haver um início de mudança de paradigma, passando-se de uma análise 
mais capitalista presente no Produto Interno Bruto, para uma análise mais sustentável, considerando o patrimônio ecológico nacional como referência para o cálculo do Produto Interno Verde.

\section{A PROTEÇÃO AMBIENTAL E OS EFEITOS DO CAPITALISMO}

Para Habermas "as crises surgem quando a estrutura de um sistema de sociedade admite menos possibilidades de resolver problemas que as requeridas para sua conservação”, atacando a integração sistêmica. O capitalismo liberal organiza-se em torno da "relação entre trabalho assalariado e capital” e está fundado no "sistema do direito privado". Como efeito do capitalismo, a economia institucionaliza seus instrumentos (bens, capitais e trabalho) dentro do território do Estado, gerando um sistema político-econômico que faz com que as relações de classe fiquem despolitizadas e que o poder tente se manter anônimo. Consequentemente, o Estado passa a ser coadjuvante em um cenário no qual o mercado é protagonista e, ainda, o Estado passa a estar a serviço do mercado, com o papel de manter as condições de produção e de valorização do capital. (HABERMAS, 1999, p. 21, 50). Assim, a riqueza pública é objeto de apropriação privada, o que impede que as decisões políticas tomadas nesse modelo sejam “suscetíveis de um consenso racional”, pois não seria resultado do interesse de todos. (McCARTHY, 1998, p. 414.)

O mercado tenta fazer com que a sociedade aceite essa realidade, enfatizando seus benefícios em relação ao crescimento econômico. O problema envolve as claras contradições entre a ideia e a realidade, que tornam o sistema capitalista vulnerável aos problemas do autogoverno, resultando numa crise sistêmica. "No capitalismo liberal as crises se apresentam na forma de problemas econômicos de autogoverno não resolvidos”, que ameaçam a integração social. (HABERMAS, 1999, p. 53-55)

Nas sociedades em que os efeitos do capitalismo começaram a ser sentidos mais tarde, houve um rápido processo de crescimento, gerando problemas de "ruptura do equilíbrio ecológico, a quebra dos requisitos de congruência do sistema da personalidade (alienação) e a carga explosiva das relações internacionais”. Em uma visão estritamente capitalista, a proteção ambiental não surge como medida necessária à preservação da vida no planeta, mas como meio de garantir a continuidade da exploração econômica: "os equilíbrios ecológicos definem um limite absoluto do crescimento”. Já os equilíbrios antropológicos são menos perceptíveis, pois seus limites somente são alcançados “à custa de uma transformação da identidade sociocultural 


\section{PRODUTO INTERNO VERDE (PIV) COMO ALTERNATIVA PARA A SUSTENTABILIDADE BRASILEIRA}

dos sistemas sociais”. Nas relações internacionais, seu equilíbrio está em risco em virtude do crescimento das forças produtivas, que podem ser utilizadas para destruição. (HABERMAS, 1999, p. 80)

O crescimento econômico tende a buscar técnicas que possibilitem utilizar a maior quantidade de energia para possibilitar o "incremento da produtividade do trabalho". Nessa perspectiva, a acumulação do capital permitiu a institucionalização “espontânea” do crescimento econômico, afastando a necessidade de um autogoverno consciente para que ocorresse referido crescimento. No entanto, os "mecanismos de crescimento estabelecidos impõem o incremento da população e da produção em escala mundial”, fazendo com que as consequências do capitalismo adquiram vigência global. As atividades econômicas, em compasso com o aumento populacional, leva a uma crescente exploração da natureza, limitada pela finitude dos bens ambientais “(por ejemplo, la superficie terrestre acondicionable para la vida humana, la provisión de agua potable y de medios de alimentación; además, materias primas no renovables, como minerales y combustibles)", e pela existência de "sistemas ecológicos no reemplazables, que absorben residuos como desechos radioactivos, dióxido de carbono o calor.” (HABERMAS, 1999, p. 81-82)

Os efeitos do capitalismo provenientes de crescimento econômico desequilibrado, dessa forma, gera o aumento da exploração dos bens ambientais, limitados por serem finitos e não renováveis. Isso leva à necessidade de preocupar-se com a proteção ambiental para melhor aproveitamento dos bens ambientais para que sejam utilizados moderadamente, de maneira que o meio ambiente não seja prejudicado.

Os problemas que surgem dizem respeito às reais informações sobre o crescimento da população (não se sabe o limite máximo de capacidade da Terra), da produção industrial (não é possível prever, com precisão, o desenvolvimento tecnológico, nem as matérias primas que poderão ser recuperadas), da exploração dos recursos naturais e da deterioração do ambiente. Mas é possível saber que o crescimento gera aquecimento global e aumento do consumo de energia. Ou seja, mesmo que seja difícil verificar, empiricamente, os prazos críticos da deterioração ambiental, é possível vislumbrar o "crescimento exponencial da população e da produção”, o que resultará num choque “com os limites da capacidade biológica do ambiente”. (HABERMAS, 1999, p. 82-83)

Isso exige das sociedades capitalistas evitar os perigos ecológicos, instituindo “imperativos de limitação do crescimento”. Isso implicaria, porém, em abandonar seu “princípio de organização, já que a reconversão do crescimento capitalista espontâneo para um 
crescimento qualitativo exigiria planejar a produção atendendo aos bens de uso”, o que infringiria a lógica do sistema. (HABERMAS, 1999, p. 83)

O ser humano, ao perceber que os bens ambientais são finitos, deveria começar a agir em prol do equilíbrio entre o desenvolvimento econômico e a proteção ambiental. Mesmo que a lógica do sistema capitalista seja quebrada, o Estado deve compensar, pela via política, as consequências do processo de acumulação. Dessa forma, o Estado consegue assumir, ao menos parcialmente, efeitos externos de atividades econômicas privadas “(por ejemplo, el deterioro del ambiente), o asegura, con medidas políticas de carácter estructural, la capacidad de supervivencia de sectores en peligro (por ejemplo, la minería o la economía agraria)”. (HABERMAS, 1999, p. 83)

Um exemplo de atuação do Estado ocorre no âmbito de sua atividade fiscal, aumentando a carga tributária para compensar os custos externos de produção, como a deterioração ambiental gerada pelas empresas privadas. Dessa forma, o Estado desenvolveria duas tarefas simultâneas: de um lado faria a coleta de impostos em detrimento dos ganhos privados, aplicando sua receita “com racionalidade suficiente [...] para evitar as perturbações de um crescimento sujeito a crises”; de outro lado, estaria legitimando essa atividade fiscal ao realizar uma arrecadação seletiva de impostos, ao tornar visível o modelo de prioridades que está implementando e ao demonstrar os rendimentos administrativos dessa atividade. "Quando o Estado fracassa na primeira dessas duas tarefas surge um déficit de racionalidade administrativa; e se fracassa a respeito da outra, se origina um déficit de legitimação”. (HABERMAS, 1999, p. 111-112)

Andreas Krell (2008) apresenta uma situação na qual fica clara a preponderância de intenções capitalistas que têm causado ruptura do equilíbrio ecológico. Ele analisa as dificuldades da proteção do patrimônio ambiental na zona costeira, com ênfase para o litoral do município de Maceió, no estado de Alagoas. A crise do capitalismo tardio apontada por Habermas parece estar bem presente nesse exemplo. O turismo desenvolvido no litoral brasileiro, especialmente no Nordeste, tem chamado a atenção do mercado e aumentado os investimentos econômicos nessa região. Consequentemente, diversos impactos ambientais passaram a ser percebidos no litorial: "loteamentos e prédios à beira-mar; estradas com pistas que atingem diretamente as praias, clubes e restaurantes cujas estruturas literalmente invadem o mar, bares e barracas na orla que produzem lixo, esgoto e ruídos”. (KRELL, 2008, p.272)

Esse crescimento ocorre sem planejamento, gerando uma urbanização desordenada do litoral, com todas as consequências de más condições sanitárias, degradação de ecossistemas e exclusão social da população de baixa renda. Isso ocorre em virtude do avanço dos interesses 


\section{PRODUTO INTERNO VERDE (PIV) COMO ALTERNATIVA PARA A SUSTENTABILIDADE BRASILEIRA}

econômicos e da omissão do Estado, que deveria planejar e fiscalizar a ocupação litorânea. (KRELL, 2008, p. 272-273)

Para realizar o efetivo planejamento ambiental, o Estado deve realizar quatro atividades básicas:

(1) Atividade de planejamento: voltado a programar as atividades do setor público para alcançar determinados fins, mediante a previsão dos instrumentos e do prazo para sua execução;

(2) Atividade de intervenção, que busca restringir direitos dos cidadãos, como a necessidade de licença prévia para a execução de determinadas atividades;

(3) Atividade de promoção, por meio da qual orienta, ou até ordena, a realização de certas condutas ou atividades, por meio de estímulos econômicos como o aumento ou redução de tributos;

(4) Atividade de negociação, que pressupõe a realização de acordos formais ou informais entre a Administração e os governados, como são exemplos os Termos de Ajustamento de Conduta entabulados com a participação do Ministério Público. (SOUZA, 2009, p. 45-46)

Krell traz, ainda, o exemplo do Código de Edificações e Urbanismo de Maceió (AL), de 2004, que revogou o anterior, de 1985. No Código anterior havia a previsão de rejeição ou modificação de qualquer projeto de loteamento ou desmembramento se isso fosse necessário para realizar a defesa do meio ambiente. Essa previsão, no entanto, "dificilmente foi utilizada por parte da prefeitura maceioense”. E, como se não bastasse a ineficácia daquela previsão legislativa, essa “ideologia de proteção da paisagem do litoral maceioense [...] foi simplesmente abandonada” pelo novo Código, que elegeu a edificação como a meta final do processo urbano. Ou seja, o objetivo do Código de Urbanismo é a edificação e não mais a proteção ambiental, ou as quatro necessidades fundamentais da vida do ser humano, prevista na Carta de Atenas de 1933: habitar, trabalhar, recrear e circular. (KRELL, 2008, p. 277-279)

Os alertas relacionados ao Município de Maceió revelam a constatação de Habermas em relação à crise do modelo capitalista. Uma população crescente, deteriorando uma paisagem e recursos naturais finitos e não renováveis em prol de interesses econômicos. Em face dessa realidade, ao Estado cabe entender os "efeitos extremos da economia privada”, como a deterioração do ambiente, e assegurar, com "medidas políticas de caráter estrutural, a capacidade de sobrevivência de setores em perigo” (HABERMAS, 1999, p. 83), como o ecossistema atingido e a população de baixa renda alijada da nobre região litorânea. (KRELL, 2008, p. 281) 


\section{PRODUTO INTERNO VERDE (PIV): UMA TENTATIVA DE MITIGAÇÃO DO CAPITALISMO FRENTE À SUSTENTABILIDADE}

Na vida em sociedade não pode ocorrer o desenvolvimento econômico em detrimento do meio ambiente, até mesmo diante “dos efeitos perniciosos, quando não irremissíveis, produzidos pelo núcleo econômico da ideia desenvolvimentista”, vindo o desenvolvimento sustentável buscar compatibilizá-lo “com o imperativo da preservação do meio ambiente”. (AZEVEDO, 2000, p. 58-59)

Por isso um dos princípios que fundamentam o ordenamento jurídico é o desenvolvimento sustentável, “cuja característica principal consiste na possível e desejável conciliação entre o desenvolvimento, a preservação do meio ambiente e a melhoria da qualidade de vida”. Compatibiliza-se, desse modo, a proteção ambiental e o desenvolvimento, o que "significa considerar os problemas ambientais dentro de um processo contínuo de planejamento” que possibilite “a gestão racional dos recursos naturais” (MILARÉ, 2005, p. 5253). O desenvolvimento sustentável deve ser visto, assim, sob três pilares: a) o bem-estar social; b) a prosperidade econômica; e c) a proteção ambiental. (LOVELOCK, 2006, p. 16-17)

O princípio do desenvolvimento sustentável exige do Estado um papel ativo que impeça a aplicação do conceito liberal de desenvolvimento (até mesmo diante da "crise do capitalismo tardio” apontada por Habermas, conforme acima estudado.), de forma a fazer prevalecer os valores ambientais. "Devemos lembrar que a ideia principal é assegurar existência digna, através de uma vida com qualidade. Com isso, o princípio não objetiva impedir o desenvolvimento econômico”, mas minimizar a degradação ambiental promovida pela atividade econômica, e promover a justiça social. (FIORILLO, 2010, p. 79, 87)

A necessidade de o Estado desempenhar um papel ativo (SOUZA; HARTMANN; SILVEIRA, 2015) na proteção ambiental exige-lhe uma agenda mínima de ação política que envolva: a promoção da educação ambiental “com ênfase nos ideais e atributos de uma sociedade sustentável”; o incentivo a movimentos de ação social voltados à cidadania e ao ambientalismo; criar normas que influenciem “o uso sustentado dos recursos naturais e coíbam o dano ambiental”; reorientar a construção e a aplicação do conhecimento, para que este voltese ao estudo da biodiversidade e à aplicação de sua preservação e a um comportamento consciente e ético em relação ao meio ambiente; “incentivar a inovação tecnológica” voltada à prevenção e recuperação ambiental, e “à produção de bens com alta durabilidade e baixo custo 


\section{PRODUTO INTERNO VERDE (PIV) COMO ALTERNATIVA PARA A SUSTENTABILIDADE BRASILEIRA}

ambiental”; incentivar a livre economia promotora de benefícios ambientais; aprimorar os “estudos e processos de avaliação de impacto ambiental”; assegurar a preservação da diversidade cultural; propiciar a melhoria da qualidade de vida e a eliminação da violência. (ALMEIDA JUNIOR, 2002, p. 47-48.)

O Estado tem dificuldade na prevenção de riscos, pois, seja agindo, seja se omitindo, de alguma forma acaba por participar da produção de novos riscos, "condicionados pela ciência e pela técnica. Os riscos inerentes à força nuclear ou à técnica genética colocam o problema da tomada de providências - também por parte do legislador - para proteger, de modo advocatício, os interesses das gerações futuras.” Os especialistas têm tido dificuldade em analisa e prever os riscos, gerando um déficit "na capacidade de elaboração, vontade de ação e velocidade de reação da administração encarregada de prevenir os riscos”. (HABERMAS, 2003, p. 176)

Essa realidade ocorre, até mesmo, no Estado Social, que se imagina seria o modelo apropriado para combater o desenvolvimento meramente econômico. No entanto, é do Estado que se esperaria a proteção da geração atual e das futuras contra os riscos trazidos por atividades como a energia nuclear e a utilização de técnicas genéticas. Para isso, o Estado precisa investir em ciência e tecnologia para prever os riscos e ser capaz de elaborar instrumentos para agir e reagir a eles. Isso "exige que o Estado não gere o dano ambiental (...) e que impeça que outros promovam a degradação (...).” (SOUZA; HARTMANN; SILVEIRA, 2015, p. 369)

Em outras palavras, o Estado tem a obrigação de melhorar a qualidade de vida por meio do "planejamento e instrumentalização de estratégias que” permitam medir o “melhoramento do nível de vida” acompanhado “do termômetro social das medições de campo, instrumentadas através de pesquisas, censos e questionários a habitantes de localidades representativas das distintas regiões do país”. (LORENZETTI, 2010, p. 69-70)

“A preservação do meio ambiente para as presentes e futuras gerações é um direito de todos. Em contrapartida, também é um dever imposto ao poder público e à sociedade como um todo pela CR/88.” (SOUZA; HARTMANN; SILVEIRA, 2015, p. 369). Assim, além do dever do Estado é necessário vislumbrar, também, a atuação da coletividade. O pano de fundo (no qual está inserido o princípio do desenvolvimento sustentável) que confere o "correto direcionamento valorativo [é] oferecido pela Constituição, especialmente por seus princípios fundamentais”. No que se refere à proteção ambiental, tanto o art. 225 da CRFB/88 como outros dispositivos constitucionais e infraconstitucionais devem orientar a formação de outras normas ambientais. "Decorre daqui a tese de que a política ambiental não prescinde apenas da atuação 
do poder público, mas de ações solidariamente responsáveis que envolvam tanto o Estado quanto a coletividade”. (LEAL, 2009, p. 171-172)

Isso exige também do ser humano, individualmente, uma revisão de seu modo de “perceber, pensar e agir em relação ao mundo em todas as suas dimensões”, alterando seus valores, conhecimento e ação em relação ao meio ambiente. Essa mudança de paradigma deve levar à realização prática do desenvolvimento sustentável, utilizando como instrumentos “a educação, o direito, a inovação tecnológica e os movimentos de ação social”. (ALMEIDA JUNIOR, 2002, p. 46)

Percebe-se que “os projetos desenvolvimentistas e de 'modernização' frequentemente afetam direitos básicos (como alimentação, saúde, instrução) e valores culturais e o bem-estar das comunidades", gerando “empobrecimento, endividamento, deslocamento e perda de terra, fome e enfermidades, discriminação e exclusão social... Daí a importância da participação, dos direta e indiretamente afetados e interessados, na elaboração e execução dos próprios projetos de desenvolvimento". (TRINDADE, 1993, p. 202)

Há uma crescente compreensão do ser humanos a respeito das limitações dos bens ambientais e, por isso, embora ainda em escala insuficiente, tem aumentado a preocupação em viver saudavelmente e em harmonia com a natureza, o que concretiza o entrosamento do desenvolvimento com a preocupação ecológica. O desenvolvimento ecologicamente sustentável, assim, busca o equilíbrio do desenvolvimento econômico, para que não haja desperdício dos recursos naturais. Ou seja, deve-se buscar um desenvolvimento compatível com o equilíbrio ambiental, sem deixar de haver a satisfação das necessidades e interesses humanos, devendo ficar atentos ao alerta de consequências e ao risco que a perpetuação da espécie tem sofrido, diante do "crescimento desordenado da economia mundial, [da] constatação do possível esgotamento dos recursos naturais, [da] deterioração da qualidade de vida, [do] aumento da população, [do] aparecimento da chamada sociedade de massas, etc.”. (FIDELLIS, 1996, p. 213)

A Lei 13.493, de 17 de outubro de 2017, que institui o PIV, parece demonstrar uma preocupação pela proteção ambiental proveniente da grave ameaça que têm sofrido os bens ambientais. $\mathrm{O}$ art. $2^{\circ}, \S 2^{\circ}$, determina uma ampla discussão com a sociedade, o que permite a conscientização dos participantes, levando-os a entender a necessidade do desenvolvimento ecologicamente sustentável. Para isso, “é imprescindível divulgar, por meio da educação ambiental e da gestão democrática e sustentável das cidades, as normas relativas ao meio ambiente” e as informações relacionadas aos bens ambientais. Isso permitirá a formação de “cidadãos conscientes de seus direitos e deveres, capazes de agir em prol da preservação do 


\section{PRODUTO INTERNO VERDE (PIV) COMO ALTERNATIVA PARA A SUSTENTABILIDADE BRASILEIRA}

meio ambiente e, assim, alcançar efetivamente os desenvolvimentos local e global”. (SPAREMBERGER; MARTINS, 2008, p. 161)

A proteção ambiental permite uma equidade intergeracional e volta-se a um desenvolvimento ecologicamente sustentável, definido como a harmonia entre o desenvolvimento das atividades humanas e a preservação da natureza (SANTOS, 1997, p. 94), visando assegurar as necessidades mínimas do presente modo de vida, sem comprometer fatalmente o crescimento das futuras gerações, ou como preceitua o Princípio n. ${ }^{0} 3$, da Declaração do Rio de Janeiro/92: “O direito ao desenvolvimento deve ser realizado de modo a satisfazer as necessidades relativas ao desenvolvimento e ao meio ambiente das gerações presentes e futuras”. (MACHADO, 1994, p. 47)

O equilíbrio entre as atividades humanas e a proteção ambiental permite a conservação da biodiversidade e, consequentemente, garante a sobrevivência das espécies (dentre as quais o ser humano”, pois a destruição dos ambientes naturais levará à perda das fontes vitais de recursos. "Se há uma organização social paralela aos avanços tecnológicos, o desenvolvimento pode direcionar-se a um crescimento econômico sem que o meio ambiente seja ofendido.” (SOUZA, 2013, p. 135-136)

No ordenamento jurídico brasileiro a principal incentivadora desse nível de desenvolvimento é a Constituição Federal, que em seu art. 225, caput, declara como direito de todos o meio ambiente ecologicamente equilibrado (o que inclui a diversidade do patrimônio genético - inciso II), bem como protege, especificamente, algumas áreas onde se concentram nichos biodiversos, como a Floresta Amazônica e a Mata Atlântica (§ 4. $\left.{ }^{\circ}\right)$. As diretrizes para o alcance do desenvolvimento sustentável foram dadas pela Agenda 21. Esse foi o nome dado a um documento que surgiu da Conferência das Nações Unidas sobre o Meio Ambiente e Desenvolvimento de 1992, celebrada no Rio de Janeiro, que definiu o desenvolvimento sustentável "como sendo aquele que atende as necessidades do presente sem comprometer a possibilidade de as gerações futuras atenderem suas próprias necessidades.” (SANTOS, 1997, p. 96)

O projeto de lei que deu origem à Lei do PIV foi elaborado quase 20 anos depois da Rio 92, em preparação à Rio+20, conforme consta em sua Exposição de Motivos:

Em junho 2012, será realizada no Brasil a “Rio+20” - Conferência das Nações Unidas sobre Desenvolvimento Sustentável. O objetivo da Conferência é “assegurar um comprometimento político renovado com o desenvolvimento sustentável, avaliar o progresso feito até o momento e as lacunas que ainda existem na implementação dos 
resultados dos principais encontros sobre desenvolvimento sustentável, além de abordar os novos desafios emergentes”.

Os dois temas em foco na Conferência serão: a economia verde no contexto do desenvolvimento sustentável e da erradicação da pobreza, e o quadro institucional para o desenvolvimento sustentável. (Fonte: http://www.rio20.info/2012/objetivos-etemas).

Nesse contexto do debate sobre o mundo que queremos para a presente e para as futuras gerações, é fundamental a revisão dos critérios utilizados no cálculo das riquezas das nações. ${ }^{3}$

Para tentar convergir com esse histórico, o legislador brasileiro inovou em 2017 (aprovando o mencionado projeto de lei com algumas modificações) ao instituir o Produto Interno Verde (PIV) como ferramenta para a medição de riqueza no Brasil. Com isso, o Produto Interno Bruto (PIB) não será mais a forma isolada de medição de riquezas. Agora, existe um fator inovador que é o patrimônio ecológico nacional como ponto de referência para a identificação de riqueza nacional.

A Lei 13.493, de 17 de outubro de 2017, que institui o PIV, determina que “o órgão federal responsável pelo cálculo do Produto Interno Bruto (PIB) divulgará também, se possível anualmente, o Produto Interno Verde (PIV)”, de forma que leve em consideração, “além dos critérios e dados tradicionalmente utilizados, o patrimônio ecológico nacional”.

No Brasil, o cálculo e divulgação do PIB é atribuição do IBGE - Instituto Brasileiro de Geografia e Estatística, vinculado ao Ministério do Planejamento. Os critérios tradicionais observados pelo órgão, em consonância com padrões internacionais, deixam de lado uma das maiores riquezas do país: sua biodiversidade, sua fauna, sua flora - seu patrimônio ecológico. ${ }^{4}$

Como acima referido, parece ser um início da mitigação dos efeitos do capitalismo, pois o PIB, visto de forma isolada, representa a soma dos bens e serviços do país, indicando seu potencial econômico. No entanto, quanto mais as pessoas gastam, mais o PIB cresce. Isso pode representar um contrassenso, pois o crescimento econômico pode resultar na deterioração do meio ambiente, conforme já trabalhado. Nesse sentido também constou na mencionada exposição de motivos do projeto de lei: “O PIB - Produto Interno Bruto é atualmente o principal

$3 \quad$ Disponível

em

http://www.camara.gov.br/proposicoesWeb/prop_mostrarintegra;jsessionid=84D4408B5108BF2829D22ABF5A 38074B.proposicoesWebExterno1?codteor=949328\&filename=Tramitacao-PL+2900/2011, $\quad$ acessado em 30/03/2018.

4 Exposição de Motivos ao projeto de lei que deu origem à Lei do PIV, disponível em http://www.camara.gov.br/proposicoesWeb/prop_mostrarintegra;jsessionid=84D4408B5108BF2829D22ABF5A 38074B.proposicoesWebExterno1?codteor=949328\&filename=Tramitacao-PL+2900/2011, $\quad$ acessado em 30/03/2018. 


\section{PRODUTO INTERNO VERDE (PIV) COMO ALTERNATIVA PARA A SUSTENTABILIDADE BRASILEIRA}

índice utilizado para mensurar o crescimento econômico de países, regiões e cidades e considera o valor de todos os serviços e bens produzidos na região estudada em determinado período.”

Com a nova, o legislador determina a necessidade de considerar o patrimônio ecológico nacional como referência para o cálculo do PIV, devendo, para tanto, considerar “iniciativas nacionais e internacionais semelhantes”, pois o fator é novo e não há referência nacional para tanto, apesar de autores de outras áreas do conhecimento (como biólogos, economistas, administradores, ecólogos, dentre outros) já virem trabalhando e apontando a necessidade de se considerar a riqueza natural do Brasil para o cálculo do PIB. Com a instituição do PIV, o cálculo do PIB deverá considerar o quanto se perdeu ambientalmente em decorrência da produção de riqueza gerada pela produção nacional, que gera a informação da produção interna nacional.

Merico (2008) já vinha apontando a necessidade de se alterar a forma de análise da riqueza nacional considerando, para tanto, os limites estabelecidos pela biosfera, uma vez que os bens ambientais são limitados e dependem de uma interrelação para que continuem a existir em equilíbrio. Assim, a busca por essa inserção configura um novo paradigma socioeconômico para o alcance da sustentabilidade.

A Lei ainda aponta a necessidade de o PIV possibilitar "a convergência com sistemas de contas econômicas ambientais adotados em outros países”, de forma que seja possível comparar esses resultados. Assim, será possível criar um parâmetro que ultrapasse as fronteiras nacionais e sirva de referência para a convergência com outros programas ambientais nacionais ou definidos por instituições e agentes globais.

Há que se fazer uma ressalva para a necessidade de a metodologia para o cálculo do PIV ser amplamente discutida com a sociedade e as instituições públicas, como prevê determina o $\S 2^{\circ}$ do artigo $2^{\circ}$, antes dele ser considerado um sistema de contas econômicas ambientais e ser oficialmente adotado no Brasil, permitindo maior participação da sociedade.

\footnotetext{
A norma ambiental elaborada com participação é mais eficiente, pois contém os instrumentos dados por seus próprios destinatários. Da mesma forma, é eficaz, pois permite aos governados conhecer seu conteúdo com antecedência e, por ter participado de sua construção, percebe que o Poder Público não está agindo de forma autoritária. Além disso, a comunidade que participa se torna mais consciente das necessidades ambientais expostas e da norma que ajudou a produzir. (SOUZA, 2013, p. 155)
}

A iniciativa legal é recente e possui apenas três artigos, sendo o terceiro sobre a vigência. Ou seja, a norma nova é apenas uma ideia quanto à possibilidade de se calcular a 
riqueza do Brasil considerando o seu patrimônio ecológico. A lei não aponta como deverá ocorrer tal aplicação, pois depende de regulamentação e da participação da sociedade e das instituições públicas que devem discutir amplamente sobre o PIV. De qualquer forma, parece representar o início de uma mitigação dos efeitos que o capitalismo costuma produzir sobre os bens ambientais.

\section{CONSIDERAÇÕES FINAIS}

A Lei $n^{0} 13.493$ de 2017 inova ao trazer uma forma diferente de análise para a produção de riqueza no Brasil, mas ainda há a necessidade de se evoluir muito para a compreensão dessa nova forma de ver. Enquanto o tema avança, será possível perceber se a sociedade e as empresas estarão preparadas para receber tal inovação, pois poderá influenciar o equilíbrio social e econômico. Por mais que esses sejam desiguais e desequilibrados quanto à distribuição de igualdades, possuem um mercado que precisa adaptar-se a tais novidades e uma cultura popular que precisa ser mais fraterna e menos egoísta.

Além disso, é necessário rever a atuação dos mercados e o alcance do direito de propriedade, ambos buscando o equilíbrio ecológico e a qualidade de vida (como previsto no art. 225 da Constituição brasileira). O reconhecimento de uma função socioambiental da propriedade é resultado desse caminho a um Estado que democratiza a gestão ambiental, reduzindo sua concepção individual para enfatizar os interesses da coletividade. Essa modificação na noção de propriedade contribui para uma nova visão a respeito do lucro, do abuso do domínio econômico e da utilização dos meios de produção, não mais voltados a meros benefícios econômicos, mas também sociais e ambientais, inclusive com relação a gerações futuras. (LEITE; AYALA, 2004, p. 35-37)

Machado (2003) aponta a necessidade de serem criadas Políticas de Governo para a sustentabilidade. Por exemplo, há a necessidade de o desenvolvimento "imitar os processos da natureza tanto quanto possível”, ou seja, existem dinâmicas naturais que devem ser entendidas pelo ser humano, como o ciclo da água e o período de retorno de eventos climatológicos intensos. Deve ainda, desencorajar atividades que causem ameaças à saúde do ecossistema e à base biofísica da economia, de forma que a ineficiência, o lixo, a poluição e a dissipação de recursos esgotáveis devem ser evitados ao máximo, pois o custo ambiental por tais práticas é muito alto. 
Os sistemas políticos devem ainda, segundo Machado (2003), conciliar medidas ambientais com propostas de equidade social. Enquanto houver um degrau social significativo, parte da sociedade será exposta a problemas ambientais, sem que tenha alternativa para superar tais exposições. É o caso de operários de fábricas que são expostos a riscos do sistema de produção e suas consequências. Na maioria dos casos, essas pessoas somente aceitam tais posições de trabalho pela necessidade de renda, por mais que recebam adicionais de insalubridade, que não deixam de ser uma indenização prévia pela exposição negativa no ambiente de trabalho.

Existe ainda a necessidade de rever os hábitos de consumo e estilos de vida, atualmente ainda valorizadas no cálculo do PIB. A demanda não pode permanecer intocável. A sociedade de consumo não pode manter os níveis de aquisição de bens e serviços nos patamares atuais, pois é evidente que a quantidade de bens ambientais é esgotável e o preço pelos serviços ambientais e pela manutenção do patrimônio ecológico não estão compondo o valor final dos produtos.

É evidente a necessidade de incluir os custos ecológicos de extração, produção e depleção nos preços dos produtos comercializáveis, sob pena de não refletir-se o impacto ambiental proporcionado pelo sistema de produção e comercialização que sustentam o capitalismo mundial. Sem isso, continuará o rápido processo de crescimento acompanhado da ruptura do equilíbrio ecológico.

Há a necessidade latente de refletir sobre o crescimento econômico e seus efeitos, sob pena de a vida na terra terminar. Por tudo isso, o desempenho econômico de um país ou região deveria ser medido pela qualidade de vida e não pelo consumo material. Por essa razão, o PIV é uma "luz no final do túnel”, que, quem sabe, poderá nortear a necessidade de internalizar o valor do impacto ambiental no sistema de preços, de forma a valorizar tanto a riqueza quanto natureza, e não somente essa como matéria prima para transformação e arrecadação econômica.

De qualquer forma, a previsão de um Produto Interno Verde está longe de ter o mesmo protagonismo do Produto Interno Bruto. Existe um amplo caminho para a efetivação dessa ideia de forma que surta efeito e realmente influencie os sistemas econômicos e sociais.

\section{REFERÊNCIAS}


ALMEIDA JUNIOR, José Maria G. de. Por um novo paradigma de desenvolvimento sustentável. In: HERMANS, Maria Artemísia Arraes (coord.). Direito Ambiental: o desafio brasileiro e a nova dimensão global. Brasília: Brasília Jurídica: OAB, Conselho Federal, 2002, p. 17-50.

AZEVEDO, Plauto Faraco de. Do Direito Ambiental - Reflexões sobre seu sentido e aplicação, Revista de Direito Ambiental, a. 2, v. 19, jul-set. 2000, Editora Revista dos Tribunais, p. 5366.

BRASIL. Lei $\mathbf{n}^{\mathbf{0}}$ 13.493, de 17 de outubro de 2017, Estabelece o Produto Interno Verde (PIV), em cujo cálculo será considerado o patrimônio ecológico nacional, Diário Oficial da República Federativa do Brasil, Brasília, DF, 18 de outubro de 2017. Disponível em:<http://www.planalto.gov.br/ccivil_03/_ato2015-2018/2017/lei/L13493.htm> Acesso em 02 de abr. de 2018.

FIDELLIS, Valéria de Nazaré Santana. Meio Ambiente e Desenvolvimento: Elementos para a Análise da Funcionalidade do Direito Positivo e do Estado na Atualidade, Cadernos de PósGraduação em Direito, n. 3, Belém: Programa de Pós-Graduação em Direito, 1996.

FIORILLO, Celso Antonio Pacheco. Curso de Direito Ambiental Brasileiro. 11. ed., rev., atual. e ampl. São Paulo: Saraiva, 2010.

HABERMAS, Jürgen. Direito e Democracia: entre facticidade e validade, volumes I e II, 2.ed.; tradução: Flávio Beno Siebeneichler. Rio de Janeiro: Tempo Brasileiro, 2003.

HABERMAS, Jürgen. Problemas de legitimación en el capitalismo tardío. Trad. José Luis Etcheverry. Madrid: Ediciones Cátedra, 1999.

KRELL, Andreas J. A falta de sustentabilidade jurídico-ambiental da ocupação do litoral brasileiro pela construção civil. In: DAIBERT, Arlindo (org.). Direito Ambiental Comparado. Belo Horizonte: Editora Fórum, 2008. p. 271-307. 
LEAL, Rogério Gesta. Condições e Possibilidades Eficaciais dos Direitos Fundamentais Sociais: os desafios do Poder Judiciário no Brasil. Porto Alegre: Livraria do Advogado Editora, 2009.

LEITE, José Rubens Morato; AYALA, Patryck de Araújo. Novas Tendências e Possibilidades do Direito Ambiental no Brasil”. In: WOLKMER, Antonio Carlos; LEITE, José Rubens Morato (orgs.). Os “Novos” Direitos no Brasil: natureza e perspectivas: uma visão básica das novas conflituosidades jurídicas. São Paulo: Saraiva, 2003.

LEITE, José Rubens Morato; AYALA, Patryck de Araújo. Direito Ambiental na Sociedade de Risco. 2.ed., rev., atual. e ampl. Rio de Janeiro: Forense Universitária, 2004.

LORENZETTI, Ricardo Luis. Teoria Geral do Direito Ambiental. Trad. Fábio Costa Morosini e Fernanda Nunes Barbosa. São Paulo: Editora Revista dos Tribunais, 2010.

LOVELOCK, James. A vingança de Gaia. Tradução de Ivo Korytowski. Rio de Janeiro: Intrínseca, 2006.

MACHADO, Paulo Afonso Leme. Direito Ambiental Brasileiro. $10^{\circ}$ ed. São Paulo: Malheiros, 2003.

MACHADO, Paulo Affonso Leme. Estudos de Direito Ambiental. São Paulo: Malheiros, 1994.

McCARTHY, Thomas. La Teoria Critica de Jürgen Habermas. Madrid: Tecnos, 1998.

MERICO, Luiz Fernando Krieger. Economia e sustentabilidade: o que é, como se faz. São Paulo: Edições Loyola, 2008.

MILARÉ, Édis. Direito do Ambiente: doutrina, jurisprudência, glossário. 4. ed. rev., atual. e ampl. São Paulo: Editora Revista dos Tribunais, 2005. 
PELIZZOLI, Marcelo Luiz. A emergência do paradigma ecológico: reflexões éticofilosóficas para o século XXI. 2.ed. Petrópolis, RJ: Vozes, 1999.

SANTOS, Antônio Silveira R. dos. Biodiversidade. Desenvolvimento Sustentável, Revista de Direito Ambiental, a.2, n.7, jul-set/1997, Editora Revista dos Tribunais, p. 94-101.

SOUZA, Leonardo da Rocha de. A consideração dos ausentes à deliberação ambiental: uma proposta a partir da ética do discurso de Jürgen Habermas. Rio de Janeiro: Lumen Juris, 2013.

SOUZA, Leonardo da Rocha de; HARTMANN, Débora; SILVEIRA, Thais Alves da. Dano ambiental e a necessidade de uma atuação proativa da Administração Pública. Revista Veredas do Direito, v. 12, p. 343-373, 2015.

SOUZA, Leonardo da Rocha de. Direito Ambiental e Democracia Deliberativa. Jundiaí: Paco Editorial: 2013.

SOUZA, Leonardo da Rocha de. Tributação e Custeio da Atividade Estatal de Proteção do Meio Ambiente, Revista do Curso de Direito da FSG, Caxias do Sul-RS, a. 3, n. 6, jul./dez. 2009, p. 41-56.

SPAREMBERGER, Raquel Fabiana Lopes; MARTINS, Ezequiel. Desenvolvimento e Direito Ambiental: a gestão democrática das cidades para a sustentabilidade. In: PEREIRA, Agostinho Oli Koppe; CALGARO, Cleide (org.). Direito Ambiental e Biodireito: da modernidade à pósmodernidade. Caxias do Sul, RS: Educs, 2008, p. 149-183.

TRINDADE, Antônio Augusto Cançado. Direitos Humanos e Meio Ambiente: Paralelo dos Sistemas de Proteção Internacional. Porto Alegre: Sérgio Antonio Fabris Editor, 1993. 